Appl. Set-Valued Anal. Optim. 3 (2021), No. 1, pp. 1-2

Available online at http://asvao.biemdas.com

https://doi.org/10.23952/asvao.3.2021.1.01

\title{
PREFACE \\ A SPECIAL ISSUE ON NONLINEAR OPERATOR THEORY: A DEDICATION TO CHARLES E. CHIDUME
}

Professor Charles E. Chidume is an outstanding mathematician and a leading expert working on the theory of fixed points of nonlinear operators. Professor Charles E. Chidume obtained his bachelor degree from the University of Nigeria, Nigeria in 1973. In 1977, He obtain his M.Sc. from the Queen's University, Canada. In 1984, he obtain his Ph.D. from the Ohio State University, USA. Now, he is a Professor and the Head of the Department of Pure and Applied Mathematics, African University of Science and Technology, Abuja, Nigeria.

Professor Charles E. Chidume is a Fellow of The World Academy of Sciences (FTWAS), a Fellow of the Nigerian Academy of Science (FAS), and a Fellow of the Nigerian Mathematical Society (FNMS). Professor Charles E. Chidume is a passionate teacher, research mentor, and motivator. He gave many invited talks in Canada, Israel, USA, and many countries in Europe and Africa. He has supervised more than 20 Ph.D. students in more than 7 countries. Furthermore, he has served as an editor for many international peer-reviewed journals, such as, Journal of Mathematical Analysis and Applications, Fixed Point Theory and Applications, and Journal of Nigerian Mathematical Society. In 2009, Professor Charles E. Chidume published the famous monograph entitled "Geometric Properties of Banach Spaces and Nonlinear Iterations", by Springer-Verlag, London. This monograph provides a comprehensive overview on fixed points of nonlinear operators.

Professor Charles E. Chidume solved many important open problems in Nonlinear Operator Theory. We next list some of them. In 1981, he proved that the Mann sequence for nonexpansive mappings is uniformly asymptotically regular in any real normed space provided that the domain of the mapping is bounded (Houston J. Math. Vol. 7 (1981) 345-355). In 2001, he gave (with S. A. Mutangadura) an example to show that the Krasnoselskii-Mann iteration sequence will not always converge strongly to a fixed point of a Lipschitz pseudo-contractive mapping (Proc. Amer. Math. Soc. 129 (2001), 2359-2363). This paper has been cited more than 173 times according to the Web of Knowledge, Clarivate Analytics. In 2001, he (in collaboration with Habtu Zegeye, who is his former Ph.D student) provided an iterative algorithm for approximating solutions of the Hammerstein equation in Banach spaces when the operators involved are of the accretive type (Abstract and Applied Analysis, 2003 (2003), 353-365). As far as we know, this is the unique algorithm used today for such problems. In 2004, he (in collaboration

(C)2021 Applied Set-Valued Analysis and Optimizaton 
with Habtu Zegeye) studied an iteration process for approximating zeros of $m$-accretive mappings and proved that the sequence of generated by the iterative process is an approximate fixed point sequence (Proc. Amer. Math. Soc. 133 (2004), 851-858). This iterative sequence is now widely studied and applied to approximate solutions of several nonlinear equations. Definitely, his versatility and insight will achieve an unpredictable phase in the future.

Finally, we express our most sincere gratitude to all the authors and referees who made this special issue possible.

Yekini Shehu

Department of Mathematics Zhejiang Normal University, Jinhua, China E-mail address: yekini.shehu@unn.edu.ng 